\title{
Editorial: Advances in Steel Manufacturing and Processing
}

\author{
Qing Liu ${ }^{1 *}$, Jung-Wook $\mathrm{Cho}^{2}$ and Elena Pereloma ${ }^{3}$ \\ ${ }^{1}$ State Key Laboratory of Advanced Metallurgy, University of Science and Technology Beijing, Beijing, China, ${ }^{2}$ Graduate Institute \\ of Ferrous Technology, Pohang University of Science and Technology, Pohang, South Korea, ${ }^{3}$ School of Mechanical, Materials, \\ Mechatronic and Biomedical Engineering, University of Wollongong, Wollongong, NSW, Australia
}

Keywords: multi-phase slag, steel refining, casting, modelling, microstructure and property

Editorial on the Research Topic

\section{Advances in Steel Manufacturing and Processing}

Steel is one of the most widely used engineering materials in modern society owing to its superior properties, abundance, and cost-efficiency. In 2020, crude steel production reached 1.864 billion tonnes worldwide. Growing industrial demands call for an efficient, quality, and intelligent steel manufacturing process. The Research Topic "Advances in Steel Manufacturing and Processing" aims at presenting a series of articles summarizing recent fundamental understanding and technological innovation in steelmaking and processing. The issue comprises six peerreviewed manuscripts, including one review and five research articles, which involve converter steelmaking, electric steelmaking, ingot casting, continuous casting, and new steel development. The review by Lin et al. gives an in-depth overview of the new concept of multi-phase slag refining for efficient dephosphorization in the steelmaking process. The research updates are presented in terms of dissolution of solid lime in slag, the formation of phosphorus-rich solution in multi-phase slag, and the distribution of phosphorus in different phases. It is pointed out that the future study needs to address the understanding of the dissolution behavior of phosphorus-rich solid solution in the final stage of converter steelmaking; the latter features high temperature, high basicity, and high $\mathrm{FeO}$ and is critical for dephosphorization. The research team of Prof. Zhou contributed two terrific research articles focused respectively on steel melting in an electric arc furnace and heat transfer in continuous casting. Chen et al. build a multi-physics model to simulate the ingot melting by electric arc plasma, in which the moving behavior of electrodes has been taken into consideration. The results show that a stable and proper arc length is enabled by adjusting the position of the electrode, which benefits the melting and heat transfer of scrap in an electric arc furnace. A CFD-based development process was established to accurately correlate heat transfer coefficient in continuous casting in the study of Ma et al. The obtained results at different conditions are converted into a parametric database by developing GUI. This can make the prediction of heat transfer easier and more accurate in continuous casting. Xie and Shen focus on the multiphase simulation of shrinkage cavity, inclusion, and macrosegregation in a 36-ton steel ingot under the consideration of liquid phase, columnar dendrites, equiaxed grains, air, and inclusion. Interesting results have been achieved on the distribution of inclusions under the influence of macrosegregation and shrinkage. Another two papers investigate the microstructure and properties of the two special steel materials: polar steel and stainless steel. Li et al. shed light on the effect of inclusion on the corrosive performance of polar steel, which requires superior toughness and corrosion resistance in low temperature seawater. It is found that the ratio of $\mathrm{Al} / \mathrm{Mg}$ is a key parameter to evaluate the type of inclusion and its corrosive properties in Al-killed steel. Contrarily, $\mathrm{Zr}-\mathrm{Ti}$ based deoxidizer exhibits better seawater corrosion resistance in the 
comparative study. Zheng et al. employ the method of Aluminothermic reaction to tailor the microstructure of 2205 duplex stainless steel. A micro-nanocrystal composite structure can be achieved by properly adjusting the content of ferric oxide to control the volume ratio of $\alpha / \gamma$ phases and grain size in the stainless steel.

Readers can easily see from this summary that the compiled articles cover both pyrometallurgy and physical metallurgy of steel, and advanced modelling methods have been introduced in their works. These papers enable a better insight into steel manufacturing and its process. Still, there are many open questions in this large-scale industry, especially with the increasingly introduced multi-disciplinary ideas and methods.

\section{AUTHOR CONTRIBUTIONS}

QL wrote this editorial, which was revised, proof-read, and approved by all authors.

Conflict of Interest: The authors declare that the research was conducted in the absence of any commercial or financial relationships that could be construed as a potential conflict of interest.

Copyright (c) 2021 Liu, Cho and Pereloma. This is an open-access article distributed under the terms of the Creative Commons Attribution License (CC BY). The use, distribution or reproduction in other forums is permitted, provided the original author(s) and the copyright owner(s) are credited and that the original publication in this journal is cited, in accordance with accepted academic practice. No use, distribution or reproduction is permitted which does not comply with these terms. 